\title{
Using Whatsapp to develop L2 oral production
}

Janaina Weissheimer ${ }^{1}$

Vaneska Caldas ${ }^{1}$

Fábio Marques ${ }^{1}$

\begin{abstract}
This study aims to investigate how Whats App influences the development of accuracy in oral production and to assess the impact of grammar-based feedback versus content-based feedback through the referred App to improve Speaking. In order to answer our research questions - How does Whats App influence the development of accuracy in oral production? What's the impact of grammar-based feedback and content-based feedback through Whats App in the development of oral production? -, twenty-seven L2 English learners were divided into an experimental group and a control group. Both groups were exposed to activities using Whats App. However, the control group received content-based feedback, whereas the experimental group received grammar-based feedback. Through a pre and post-test, we checked if this differential in feedback influenced the participants' oral development. Results indicate that the use of Whats App as a tool to practice speaking may have a positive impact in the development of students' oral production. In addition, findings suggest that grammar-based feedback might be more effective than content-based feedback, in what concerns L2 oral production.
\end{abstract}

Keywords: oral production. Second language learning. Whats App

${ }^{1}$ Universidade Federal do Rio Grande do Norte. 


\section{Introduction}

As English teachers, we are well aware of both the importance and the difficulties of being able to speak the language fluently. On the one hand, we know one of the main reasons for students to learn a new language is to communicate orally and, without necessarily neglecting the other four skills (listening, reading, writing and culture), we can't help sharing our student's happiness when they report a conversation they have had with a native speaker ${ }^{2}$, or when they manage to understand a movie in English without subtitles. It's not by chance that the ultimate question in terms of proficiency is "Do you SPEAK English?". On the other hand, being proficient in L2 is a complex goal to achieve, especially when we take in consideration its subjectivity and the different aspects involved in the process. For students, it can be hard to build a bridge from what they learn in class to the actual production of the language.

Considering our own practice, another hindrance to the learner's oral development is the short amount of time given to face-to-face classes which, combined to the obligation of fulfilling all the pre-established contents, make it hard for teachers to give closer attention to students' speaking proficiency. Besides these adversities, the number of students per class contributes to increase the level of stress that oral activities usually generate in students, in particular the most reserved ones, or the ones who present a greater deal of linguistic difficulties.

Meanwhile, it is safe to say that the key word of the XXI century is collaboration, inspired by the easiness in accessing different contents and, mainly, in reacting to them. It is impossible to deny the contributions that digital technology has brought to people's lives (WARSCHAUER; HEALEY, 1998, PRENSKY, 2001). Nowadays, most of our daily activities are more easily done due to the available apps and software. With the internet, people started to communicate in a rapid and instant way.

In parallel, researchers (GONZÁLEZ-LLORET; ORTEGA, 2014, MATTAAR, 2014) have started to pay closer attention to the use of technology in education, especially in what concerns English as a Foreign Language (EFL). In the last few years, studies about the potential of technology-based learning have increased. From the moment a specific

\footnotetext{
2 Although we acknowledge the important discussion about how questionable the dichotomy native and nonnative speaker is, and we recognize the need to recognize different Englishes (CRYSTAL, 1997), here we are merely stating students' general views of native speakers.
} 
digital tool becomes available at any time and at any place, infinite possibilities of using it for education arise.

The use of technology in L2 learning allows an asynchronous exchange of information, which may lead to a series of benefits to the learners. First, it may contribute to increase students' autonomy. Second, it may decrease students' affective filter, building up their confidence. Third, it gives students more time to organize their answers. Fourth, it encourages students to explore the language. Fifth, it allows students time to reflect on the feedback they receive.

Technology has been reshaping teaching. In that context, WhatsApp, an instant free message app for smartphones, gains more and more space every day. According to a research conducted by Mobile Ecosystem Forum (MEF), WhatsApp is the most popular app in Brazil, approximately $76 \%$ cell phones owners use it. As reported by its official site, the App has 1,2 billion users worldwide. In Brazil, in May of the current year, 120 million people already used it.

Additionally, nowadays communication between teachers and students through WhatsApp is quite common and works for several different purposes, such as to solve doubts, to receive feedback, to fill in possible gaps from face-to-face meetings and to encourage students to feel more confident to share their productions. All the reasons listed above explain why many language teachers have been interested in finding new ways of inserting this user-friendly technology in their classes and to look at it as a helpful tool to the learning process.

Taking all the points above in consideration; that is, acknowledging the relevance of teachers/researches turning their eyes to tools which might help students to develop their oral capacity, and aiming to shed some light on how mobiles may promote learning, our goal was to investigate how WhatsApp may influence the development of accuracy in oral production. In addition, we sought to analyze the impact of grammar-based feedback and content-based feedback through WhatsApp in the development of oral production. By doing so, we were interested in answering the following research questions:

(1) How does Whats App influence the development of accuracy in oral production?

(2) What's the impact of grammar-based feedback and content-based feedback through Whats App in the development of oral production? 
In the remaining sections, we shall present a brief review of the literature followed by methods, results, and interpretation.

\section{Literature review}

The role of noticing has been widely discussed in L2 learning. Schmidt (1990) proposes the Noticing Theory, a theory which states that learners need to consciously register L2 linguistic aspects in the input to acquire them. In other words, to learn, the person needs, first, to notice there's something to be learned. According to Schmidt (1990), noticing is a personal experience. However, some studies suggested that noticing of L2 formal aspects may be facilitated by instruction (BERGSLEITHNER, 2007; ELLIS, 2009). It is important to point out that noticing does not only happen in the internalization of the input. It also happens when the learners produce the language and realize there is a gap between what they intended to say and what they, in fact, said.

In line with the importance of consciously registering the information, another factor to be considered while leaning a language is that the processes involved in its production are completely different from the ones involved in its comprehension (SWAIN, 1995). That is, it is possible to understand a language without speaking it, but, in order to speak it, the person needs to understand it first. Besides this, it is only by producing the language that the learners step out of their comfort zone, pushing the boundaries of their interlanguage, because they go from the semantic process, prevailing in comprehension, to the syntactic process, necessary to production. With that in mind, Swain (1995) proposes the Output Hypothesis, in which learners, by producing the language, trigger noticing, test their hypothesis and reflect upon the language.

However, even though noticing what needs to be learned and producing the language are fundamental elements to become proficient in L2, it is relevant to mention that learners have attentional limitations, that is, they cannot focus on different learning aspects equally without having these aspects competing for attentional resources. Therefore, in order to be orally proficient in a language, learners need to take the speaking micro abilities in consideration. Aiming to access the level of oral proficiency of an L2 learner, Skehan (1996) suggests three dimensions: accuracy (the ability to avoid errors), complexity (the 
capacity to use more advanced language) and fluency (the capacity to use language in real time).

Our research focused on accuracy. According to Skehan (1996), the lack of accuracy may result in communication breakdown, which might frustrate the learner. One of the reasons for that kind of inefficient communication might be connected to the relation between competence and performance: by being pressured to produce the language, the student makes mistakes which could have been prevented.

Considering the importance of developing students' oral proficiency, as well as the difficulties in reaching this goal (due to several reasons, such as attention limitations, limited class time, large amount of contents to be taught, individual differences), it becomes imperative to find ways to help the learners to improve speaking. We take the view that two effective forms of accomplishing such purpose might be by encouraging students to plan and by providing grammar-based feedback.

Foster and Skehan (1996) consider planning a useful pre-task activity, which can represent a positive influence in the L2 learners' level of performance. By planning an oral task, learners go through stages which help them to improve their production, such as lexical choices, thought organization and rehearsals (GUARÁ-TAVARES, 2011). In other words, while planning, the learners decide the meaning they want to convey and, subsequently, they seek to activate appropriate linguistic resources to communicate.

In what concerns to feedback, as opposed to common sense, it goes beyond error correction. It also comprehends an incentive to reflection, in the sense that the learners are able to identify the weakest points of their production, as well as what can be done to improve it. According to Ellis (1994), explicit corrective feedback is an effective way to promote learning, because when learners receive explicit feedback on their attempts to communicate, acquisition takes place. Explicit feedback not only makes the problem clear to the learner, but also contributes to the internalization of the rule.

Planning requires time. Feedback demands reflection. Oral production urges practice. In the frantic world we live in, it may be hard for L2 learners to find enough time to become proficient in a new language. That is when technology may come in handy, since it is present in our everyday life. According to several researches (WARSCHAUER, 1996; PRESNKY, 2001; MATTAR, 2014), using technology in L2 may be beneficial to the 
leaning process. Also, Suler (2004) claims that asynchronous communication may promote the disinhibition effect, that is, by not having to react immediately, the learner's affective filter decreases (KRASHEN, 1982), which promotes learning, since the learner feels more confident to produce the language.

Nowadays mobile phones are an everyday tool and researches have been looking at them as a pedagogical asset. Costa (2013), for example, investigated the potential of using mobile phones in English language teaching, through a study with 94 high school students in Piauí. The research found that the use of mobile phones, in addition to making learning more motivating, contributed to integrate students into a real learning context and to improve their English language skills, due to the free possibility of access to the activities.

Even though the use of mobile phones as an educational tool is not new, research on the potential of WhatsApp in what relates to L2 learning is fairly recent. The App itself was created in 2009. Recently, there have been some studies in what concerns to its potential towards L2 learning. For instance, studies conducted by South African researchers Ramble and Chipunza (2013) indicate that the insertion of WhatsApp in pedagogical activities increases student engagement, as well as provides the teacher with an extra channel of communication with students, since it allows the creation of communities which can be periodically fed by teachers.

In addition, the study carried out by Plana et al. (2013) - Improving learners' reading skills through instant short messages: A sample study using WhatsApp - indicates that the application increased the motivation to read in English and stimulated engagement in the activities proposed by the teacher. Likewise, Han and Keskin (2016) investigated the use of WhatsApp to reduce the anxiety of EFL learners and concluded that the application has a positive effect on language acquisition, helping to reduce the level of anxiety.

In Brazil, especially from 2014 on, WhatsApp has called the attention of L2 researchers, who see the app as a promising tool to support education (MATTAR, 2014). However, to the best of our knowledge, there is a great need of more research in this area. Therefore, this study aimed to investigate how WhatsApp influences the development of accuracy in oral production and to assess the impact of grammar-based feedback versus content-based feedback through the referred App to improve Speaking. 


\section{Methods}

The main objective of our research was to determine whether WhatsApp helps students to develop their oral production. In order to reach such a goal, we intended to answer the following research questions: How does WhatsApp influence the development of accuracy in oral production? What's the impact of grammar-based feedback and content-based feedback through WhatsApp in the development of oral production?

There is an agreement that the object of investigation of Applied Linguistics is language as a social practice (PAIVA et al., 2009). In that sense, our research contributes to the field of Applied Linguistics by attempting to solve real needs or problems, more specifically, the development of learners' oral production in the classroom. Therefore, our study has an applied nature, since it intends to generate knowledge about the practical use of WhatsApp in the classroom, in an L2 learning environment.

\section{Type of research}

Aiming to verify the impact of WhatsApp in the development of oral production, particularly in what relates to accuracy and to feedback, we analyzed quantitative data. Our research is considered semi-experimental, considering it had a control and an experimental group, pre and post-tests, but not a randomized sample of participants (NUNAN, 2007).

\section{Context of participants}

Data were collected in an extension language program, with 27 elementary level students, who had classes twice a week, with one and a half hour duration per meeting. Students' ages varied from 23 to 37 (mean: 28). The experimental group was formed by nine women and five men, while the control group had ten women and three men.

Intending to control the variables, we collected data among our own students, in the same private school, in which the same material and method are used. Moreover, the development of the activities requested that we guided the students, as well as that we kept 
frequent contact with them, mentoring them throughout the activities. All 27 participants had Smartphones and used their own devices during the data collection.

\section{Data collection procedures and instruments}

Students were randomly divided in two groups, control and experimental. Both groups were submitted to a pre and a post-test, in which their accuracy was assessed. The tests consisted of the description of a picture, for at least a minute. Such activity is based on the third part of the speaking assessment of the Cambridge Preliminary English Test (PET). PET has been chosen because it is an elementary level test, suitable to the level of the participants of our research.

Within a two-month period, both groups were encouraged to record four small audios, through WhatsApp, about pre-established themes. Students recorded the audios where was most convenient for them, and for as many times as they pleased. The experimental group received grammar-based feedback, regarding their grammatical accuracy, while the control group received content-based feedback, concerning the meaning of the message.

The themes for the recordings were always related to the ones seen in the pedagogical material during classes, such as introductions, talking about food preferences, describing a trip and advising a friend to study English. Each activity was assigned within the course of 15 days, time in which the researchers helped the students to come up with strategies to plan their messages. Students were also encouraged to rehearse their speech and to ask any questions regarding their doubts about the production of the audios. After listening to each speaking production, the researchers provided feedback (based on the group students were placed in) in Brazilian Portuguese, their native language.

\section{Data analysis procedures}

We relied on the results of both pre and post-tests to investigate whether WhatsApp influenced students' accuracy development, as well as to assess the impact of grammar-based feedback and content-based feedback to the process. In order to do so, 
first, we transcribed the pre and post-tests audios. Next, following the measure used by Mehnert (1998), we analyzed the transcriptions by counting the number of errors per 100 words, aiming to measure students' overall accuracy and to determine the impact of the two kinds of feedback. Then, we used the statistical program SPSS (Statistical Package for the Social Sciences), in which we submitted our quantitative data to the non-parametric test Wilcoxon, to determine whether the differences revealed by the mean scores between control and experimental groups achieve statistical significance. Wilcoxon has been chosen, instead of the T-test, because the data in our sample were not normally distributed, as attested by the Shapiro-Wilk test.

\section{Results and discussion}

The aim of this section is to report the results from this study, as well as to analyze and to discuss them, taking in consideration the theories presented in the literature review. We intended to investigate how WhatsApp influenced the development of accuracy in oral production and to assess the impact of grammar-based feedback versus content-based feedback through the referred App to improve Speaking.

In order to address the objectives proposed, we have formulated two hypotheses: (1) Students might make fewer mistakes in their post-tests, as compared to their pre-tests, by having been given time to plan their speaking and to record their audios freely. This rationale follows Swain (1995), who proposes the Output Hypothesis, in which learners trigger noticing by producing the language.

(2) Students might benefit more from grammar-based feedback than from content-based feedback, because the former contains direct reference to their grammar inaccuracies while the latter focuses exclusively on the content of the message. This follows Ellis (1994), whose research results reported that explicit corrective feedback represents a greater advantage on the development of oral production.

From this point on we will discuss our findings, readdressing our hypotheses and making connections between our results and the ideas voiced by the researchers we have mentioned so far. 
The data were analyzed by the statistical program SPSS (Statistical Package for the Social Sciences). As we can see from the descriptive statistics displayed on Table 1, by comparing the mean scores between the pre and the post-tests, we can already observe there was a decrease in the number of mistakes made by both the control group and the experimental one (EXPgroup post: 8,1148, EXPgroup pre: 15,7358; CONgroup post: 11,6818, CONgroup pre: 14,1562). Besides that, we can also say that such decline seems to be more substantial within the experimental group $(7,621)$ as compared to the control group (2,474). However, inferential analysis is needed in order to identify if such decrease is statistically significant or not.

\begin{tabular}{|l|c|c|c|c|c|}
\hline & $\mathrm{N}$ & Minimum & Maximum & Mean & $\begin{array}{c}\text { Std. } \\
\text { Deviation }\end{array}$ \\
\hline EXPpreaccuracy & 14 & 8,47 & 24,56 & 15,7358 & 4,68949 \\
COPpostaccuracy & 14 & 4,55 & 16,00 & 8,1148 & 2,66535 \\
CONpostaccuracy & 13 & 8,19 & 20,37 & 11,6818 & 3,01433 \\
Valid N (listwise) & 13 & 10,71 & 19,35 & 14,1562 & 2,82109 \\
\hline
\end{tabular}

Table 1: descriptive statistics of control and experimental accuracy scores.

Attempting to answer our research questions - How does WhatsApp influence the development of accuracy in oral production? What's the impact of explicit feedback and meaning feedback through WhatsApp in the development of oral production? - we submitted our data to the non-parametric test Wilcoxon, used to compare two sets of ranks from the same group of participants, that is, to find out whether the differences revealed by the mean scores between control and experimental groups achieve statistical significance. 


\begin{tabular}{|c|c|c|}
\hline & EXPpreaccuracy & CONpreaccuracy \\
& EXPpostaccuracy & CONpostaccuracy \\
\hline Difference in mean scores & $-3,107$ & $-2,510$ \\
\hline p-value Significance &, $002^{*}$ &, $012^{*}$ \\
\hline
\end{tabular}

$*$ Results are statistically significant when $\leq 0.05$

Table 2: Wilcoxon inferential statistic analysis of control and experimental accuracy score.

According to the results on Table 2, in the experimental group 13 participants, from a total of 14 , made fewer mistakes in the post-test. Within the control group, 9 participants, from a total of 13 , followed the same pattern. In addition, the difference in both groups' scores reached significance (experimental -3,107, $\mathrm{p}<, 002$; control -2,510, $\mathrm{p}<$ ,012); however, such significance was more expressive for the experimental group $(\phi, 002$ is more significant than $p$,012). Taken together, these results suggest that the group who received grammar-based feedback seems to have benefited more from the experience, as we had predicted.

Although both groups showed significant decreases, we can still argue that the grammar-based feedback was more effective, given the decrease in those students' score was more significant. In other words, the experimental group data allow us to infer that grammar-based feedback may increase students' probability of cognitively registering their mistakes and, therefore, avoid making them again in the future.

These results tend to corroborate our hypotheses. First, we had hypothesized that students in both groups would make fewer mistakes in their post-tests as compared to their pre-tests, by having been given time to plan their speaking and to record their audios freely. This was exactly what happened, since the majority of the participants seem to have made fewer mistakes in their post-tests, regardless of the group they were placed in. It seems that students were indeed able to trigger noticing and to shift from the semantic process, which prevails in comprehension, to the syntactic one, essential to the production of a language (SWAIN, 1995). In that sense, our findings go hand in hand with the Noticing Theory, proposed by Schmidt (1990), which states that learners need to consciously register L2 linguistic aspects to acquire them. 
Our results also align with Swain (1995), who claims that it is only by producing the language that students will trigger noticing and, consequently, realize what is missing from their production and how to improve it. In both groups, experimental and control, we may assume students noticed their mistakes throughout the activities and, as a consequence, made fewer of them in their post-tests, compared to the pre-tests.

Moreover, as we have discussed throughout the article, learners have attentional limitations. In other words, it is hard for them to focus on different learning aspects at the same time, especially when they are being pressured to produce the language (FAVREAU; SEGALOWITZ, 1983). That said, teachers may have an important role in helping students to overcome speaking barriers. According to some researchers (BERGSLEITHNER, 2007; ELLIS, 2009), teachers may instruct students to notice a gap between what was meant to be said and what was actually said. That way, learners will be encouraged to push the boundaries of their interlanguage and to consistently improve their oral production.

An effective way to improve oral production, as our results confirm, might be by allowing students time to plan (FOSTER AND SKEHAN, 1996; GUARÁ-TAVARES, 2011). Planning helps students to build a bridge between the meaning they want to convey and the appropriate linguistic resources they will need to use. Furthermore, it enables students to organize their thoughts and to rehearse their speech. Asynchronous communication, such as the one promoted by WhatsApp, may be a powerful ally in this process, since it releases students from having to react immediately, which, in turn, may lead them to feel more confident to produce the language. In other words, by decreasing their affective filter (KRASHEN, 1982), students may produce fewer mistakes. Therefore, our results suggest that students may benefit from the use of WhatsApp to improve L2 oral production.

Regarding our second hypothesis, we had anticipated that students would benefit more from grammar-based feedback than from content-based feedback, because the former contains direct reference to their grammar inaccuracies, while the latter simply focuses on the content. Again, our results also seem to support this hypothesis, since the 
grammar-based feedback had a more significant positive impact on students' development of oral production ${ }^{3}$, compared to content-based feedback.

Following the same thread, Swain (1995) argues that feedback has an important role in second language learning because, in general, it is an essential step to confirm learners' hypotheses. Besides, according to the researcher, feedback may guide students in rethinking and, therefore, modifying, their output. Ellis (1994) defines feedback as a response to learners' statements which contain mistakes. Such response may indicate that a mistake was made, may supply the learner with the correction or may give metalinguistic information about the nature of the mistake.

In his study, Ellis (1994) states that explicit feedback, that is, feedback that clearly indicates the problem to the student, is the most effective way of promoting learning, because when learners receive explicit feedback on their attempts to communicate, acquisition takes place. Explicit feedback not only makes the problem clearer to the student, it also contributes to the internalization of the rule. Also, receiving explicit feedback through WhatsApp, instead of face-to-face in the classroom, may be more advantageous to the students, since they are exposed to a lower degree of stress.

Similarly, results of an experimental research about the effects of implicit and explicit corrective feedback in the acquisition of the past simple tense in the English language, conducted by Ellis, Loewen and Erlam (2006) suggest that explicit feedback is more effective than the implicit one, due to the high level of consciousness that such feedback brings to the learners, by the comparison between the target language and their own production, thereby contributing to the learning process.

Explicit feedback may result in positive or negative evidence. Positive evidence translates into exposing the student to linguistic structures which are possible in the target language, whereas negative evidence encompasses the indication of which is not possible. Even though both evidences are considered relevant, the negative one is a necessary condition for the L2 development because it leads the learner to notice the mistakes (GASS, 1997; SWAIN, 1995; LIGHTBOWN, SPADA, 2006).

\footnotetext{
3 The concept of oral production as being connected to accuracy does not undermine the importance of also seeing language as social practice. In other words, we acknowledge that, alongside with cognitive aspects, interaction places an essential role in L2 learning (GASS, 1997; SWAIN, 1995).
} 
Thus, our findings seem to corroborate the literature in the field. By comparing the experimental and the control group, we may infer that, in what concerns our study, grammar-based feedback (in other words, explicit feedback) seems to be the most trustworthy one to help develop L2 oral production, which reinforces the understanding that providing explicit feedback may be a more effective way to help students to develop proficiency in L2.

\section{Conclusion}

The current study sought to investigate whether WhatsApp helps L2 students to develop accuracy in their oral production and to analyze the impact of two kinds of feedback, grammar-based and content-based, to achieve such objective. Twenty-seven students were asked to record a set of audios through WhatsApp and received different feedback about them. The experimental group, consisting of 14 students, received grammar-based feedback while the control group, consisting of 13 students, received content-based feedback.

By comparing both groups, results indicate that receiving grammar-based feedback may have a positive impact in the development of students' oral production, in what relates to accuracy. In other words, findings suggest that grammar-based feedback, that is, feedback that clearly points out grammatical inaccuracies might be more effective than content-based feedback, that is, feedback that only provides the students with general comments about the message, in what concerns L2 oral production.

Some students tend to underestimate the importance of accuracy in the development of oral production. On the one hand, teachers need to point out that the lack of accuracy may lead to inefficient communication which, ultimately, might frustrate the learner. On the other hand, pressuring students to produce the language correctly may result in unwillingness to engage in further speaking tasks. Thus, the key is to find the balance between pushing students to notice grammatical problems and giving them a safe space to experience with the language.

In order to find such balance, giving students feedback on their oral productions and helping them to identify their weakest points, as well as what they can do to improve 
them, can make a difference in promoting learning, especially because it stimulates reflection. Our modest research seems to corroborate those beliefs, since it tends to emphasize the relevance of explicit feedback to improve oral production.

That said, there are two limitations which need to be addressed regarding this study. First, our number of participants was small (27 students), which does not allow us to make steady claims based on such a restricted data set. Second, the time constraint; that is, the reduced period of time between the pre and the post-test and the lack of more time to plan and to rehearse the activities might have contributed to limit our results. Hence, findings of the present study are to be seen as suggestive rather than conclusive.

In light of the limitations mentioned above, the following suggestions are proposed. First, we believe a larger number of participants and more time to help students through the activities would translate into better results. Second, we understand that having a third group recording the audios, but not receiving any kind of feedback about them, would help us to come up with more consistently data about the importance of feedback. Going further, having a fourth group, which would not use WhatsApp, would definitely strengthen our findings.

In class, due to a number of reasons (e.g.: large number of students per class, individual differences, teacher obligation to fulfill all the pre-established contents) students usually do not have enough time to practice oral production. Knowing the importance of speaking English and eager to find ways to help students achieve such goal, teachers have looked for simple and motivating ways to encourage students to speak the language. In that sense, WhatsApp, which is already a part of students' life, may represent a great differential for both teachers and students. Teachers will be given a chance to follow the progress of each learner and students may feel more confident to speak up.

We would like to address the importance of looking at oral production not only as a means to practice the language, but mainly as an indissoluble aspect of language learning, which should not be left aside, neither by students, nor by teachers. Therefore, we hope to have contributed to the discussion regarding the use of technology in what concerns to L2 learning. The way we see it, it is only by going beyond classroom limitations that we will truly be able to help our students to thrive. We hope our small contribution helps to bring attention, and further research, to the potential of WhatsApp in L2 learning. 


\section{References}

BERGSLEITHNER, Joara Martin. Working memory capacity, noticing, and L2 speech production. Tese (Doutorado em Letras: Língua Inglesa e Linguística Aplicada). Florianópolis: Universidade Federal de Santa Catarina, 2007.

COSTA, Giselda. Santos. Mobile learning: explorando potencialidades com o uso do celular no ensino-aprendizagem de língua inglesa como língua estrangeira com alunos da escola pública. Tese (Doutorado em Letras). Recife: Universidade Federal de Pernambuco, 2013.

CRYSTAL, David. English as a global language. Cambridge: University Press, 1997.

ELLIS, Rod. A theory of instructed second language acquisition. In: Ellis, N. (Org.), Implicit and explicit learning of languages. San Diego: Academic Press, 1994.

ELLIS, Rod. The differential effects of three types of task planning on the fluency, complexity, and accuracy in L2 oral production. Applied Linguistics v. 30, nº 4, Dez. 2009.

ELLIS, Rod; LOEWEN, Shawn; ERLAM, Rosemary. Implicit and explicit corrective feedback and the acquisition of L2 grammar. Studies in Second Language Acquisition v. $28, n^{\circ} 2,2006$, p. 339-368.

FAVREAU, M.; SEGALOWITZ, N. Automatic and controlled processes in the fist - and second - language reading of fluent bilinguals. Memory \& Cognition v. 11, nº 6, 1983, p. $565-574$.

FOSTER, P.; SKEHAN, P. The influence of planning and task type on second language performance. Studies on Second Language Acquisition v. 18, n 3, 1996, p. 299-323.

GONZÁLEZ-LLORET, M., ORTEGA, L. Technology-mediated TBLT: researching technology and tasks. Amsterdam: John Benjamins, 2014.

GASS, Susan. Input, interaction, and the second language learner. Mahwah: Lawrence Erlbaum, 1997.

GUARÁ-TAVARES, Maria da Glória. Pre-task planning, working memory capacity, and L2 speech performance. Tese (Doutorado em Letras). Florianópolis: Universidade Federal de Santa Catarina, 2011.

HAN, Turgay; KESKIN, Firat. Using a mobile application (WhatsApp) to reduce EFL speaking anxiety. Gist Education and Learning Research Journal nº12, Jan.-Jun. 2016, p. $29-50$.

KRASHEN, Stephen. Principles and practice in Second Language Acquisition. Oxford: Pergamon, 1982.

LIGHTBOWN, Patsy M.; SPADA, Nina. How languages are learned. 3 ed. Oxford: Oxford University Press, 2006. 
MATTAR, João. Web 2.0 e redes sociais na educação. São Paulo: Artesanato Educacional, 2014.

MEHNERT, Uta. The effects of different lengths of time for planning on second language performance. Studies in Second Language Acquisition v. 20, 1998, p. 83-108.

NUNAN, David. Research methods in language learning. Cambridge: Cambridge University Press, 2007.

PAIVA, Vera Lúcia Menezes de Oliveira; SILVA, Marina M. dos Santos e; GOMES, Iran Felipe Alvarenga. Sessenta anos de Linguística Aplicada: de onde viemos e para onde vamos. In: PEREIRA, R.C.; ROCA, P (Org.). Linguística aplicada: um caminho com diferentes acessos. São Paulo: Contexto, 2009.

PLANA, M. G. C., ESCOFET, M. I. G.; FIGUERAS, I. T.; GIMENO, A.; APPEL, C.; HOPKINS, J. Improving learners' reading skills through instant short messages: a sample study using WhatsApp. 4th WorldCALL Conference. Glasgow, 10-13 July 2013.

PRENSKY, Mark. Digital game-based learning. Minnesota: Paragon House, 2001.

RAMBLE, Patient; CHIPUNZA, Crispen. Using mobile devices to leverage student access to collaboratively-generated resources: a case of Whatsapp instant messaging at a South African University. International Conference on Advanced ICT, 2013.

SCHMIDT, Richard. The role of consciousness in second language learning. Applied Linguistics v. 11, 1990, p. 129-158.

SKEHAN, Peter. Second language acquisition research and task-based research. In: WILLIS, Jane; WILLIS, Dave (Org.). Challenge and change in language teaching. Heinemann: Oxford, 1996.

SULER, John. The psychology of cyberspace: online disinhibition effect. 2004. Available on: <http://www.samblackman.org/Articles/Suler.pdf>. Access on: Out. 10, 2016.

SWAIN, Merril. Three functions of output in second language learning. In: COOK, G.; SEIDLHOFER, B. (Org.). Principles and practice in the study of language. Oxford: Oxford University Press, 1995.

WARSCHAUER, Mark. Comparing face-to-face and electronic communication in the second language classroom. CALICO Journal v. 13, n 2, 1996, p. 7-26.

WARSCHAUER, Mark; HEALEY, Deborah. Computers and language learning: an overview. Language Teaching v. 31, 1998, p. 57-71. 


\section{Resumo}

Este estudo tem como objetivo investigar como o WhatsApp influencia o desenvolvimento da precisão gramatical na produção oral e avaliar o impacto do feedback baseado em gramática versus feedback baseado em conteúdo através do referido aplicativo para melhorar a produção oral. Para responder às nossas questões de pesquisa - Como o Whats App influencia o desenvolvimento da precisão gramatical na produção oral? Qual é o impacto do feedback baseado em gramática e feedback baseado em conteúdo através do WhatsApp no desenvolvimento da produção oral? -, vinte e sete alunos de inglês como L2 foram divididos em um grupo experimental e um grupo de controle. Ambos os grupos foram expostos a atividades usando o Whats App. No entanto, o grupo de controle recebeu feedback. baseado em conteúdo, enquanto o grupo experimental recebeu feedback baseado em gramática. Através de um pré e pós-teste, verificamos se esse diferencial de feedback influenciou o desenvolvimento oral dos participantes. Os resultados indicam que o uso do WhatsApp como ferramenta para praticar a habilidade oral pode ter um impacto positivo no desenvolvimento da precisão gramatical na produção oral dos alunos. Além disso, os resultados sugerem que o feedback baseado em gramática pode ser mais eficaz, do que o feedback baseado em conteído, no que diz respeito à produção oral de L2.

Palavras-chave: Produção oral. Aprendizagem de inglês como L2. Whats App

Recebido em: 22/12/2017.

Aceito em: 06/06/2018. 